\title{
Hydrologic Vulnerability and Preventing Domino Effect Consequences
}

\section{Berrin Tansel*}

Florida International University, Miami, Florida, USA

Hydrologic conditions and dependency of a community to the existing state of hydrologic settings create a network of vulnerabilities with multidimensional consequences. Hydrologic vulnerability is defined by the geographic conditions which also link a series of physical, social, and economic conditions as well as the engineering infrastructure. The major disasters in the recent history provided remarkable examples where hydrologic vulnerability of communities have been tested through the consequences observed in physical, social, economic and engineering infrastructure networks. Just in the last three years the World has witnessed the oil spill in the Gulf of Mexico in 2010, earthquake in Haiti in 2010, earthquake and tsunami off the Pacific coast of Tōhoku in Japan in 2011, floods in Thailand in 2011, floods and mudslides in Rio de Janeiro in 2011, Costa Concordia cruise ship accident near Italy in 2012, hurricane Sandy in USA in 2012, Haian typhoon in Philippines in 2013, floods in Chandrapur district in Maharashtra of India in 2013, and floods in the eastern and southeastern provinces of Afghanistan in 2013. These disasters have not only showed the hydrologic vulnerability of the communities but also have produced long lasting impacts form a multitude of perspectives.

Defining and measuring hydrologic vulnerability is a complex problem. This is partly because of the complex nature of the interdependencies between physical, social, economic, cultural structures with hydrology; the need for a case-by-case assessment for each geographical location; and the range of events which can affect the hydrologic settings and its vulnerabilities. Figure 1 presents the complexity of developing a risk based methodology for assessing the hydrologic vulnerability which has to be conducted on a case-by-case basis. Some of the impacts of major disasters that have occurred several years ago are still being evaluated and may not be quantified for year to come. This is dues to the possible long term effects and/or difficulty in quantifying the impacts.

We know that certain factors increase the hydrologic vulnerability such as population density, interdependency of different systems, and geographical advantage of a location (i.e., economic, political, cultural). We also know that over time the hydrology vulnerability gradually increases due to increasing population; increasing need for food, increasing demand for energy and other resources; increasing dependency to infrastructure networks (e.g., roads, water and sewer pipelines, and power grids); climate change; and sea level rise.

Another complicated aspect of the hydrology vulnerability is the wide range of the events that need to be considered for quantifying the vulnerability of a community. On one hand, there are natural events such hurricanes, tsunamis, and climate change; on the other hand there are man-made events such as oil spills, explosions and pollution. The level of vulnerability for a flood event is different from that for climate change. As a result, the occurrence/development time, propagation profiles of impacts, and magnitudes of impacts experienced by the community would be significantly different depending on the characteristics of the triggering events, interdependencies between the hydrologic vulnerability and the vulnerabilities of other systems that are directly or indirectly associated with the hydrologic setting, geographical conditions, as well as social and cultural characteristics of the community.
With each disaster, there is an increasing awareness of the magnitudes of the impacts and long lasting consequences. The recent disasters have shown the range and levels of vulnerabilities of different communities worldwide. Figure 2 presents the progression of awareness for addressing the needs. At present, from scientific and policy perspectives we are at stage 2 for dealing with hydrologic vulnerability. However, the probabilities of events that affect hydrologic

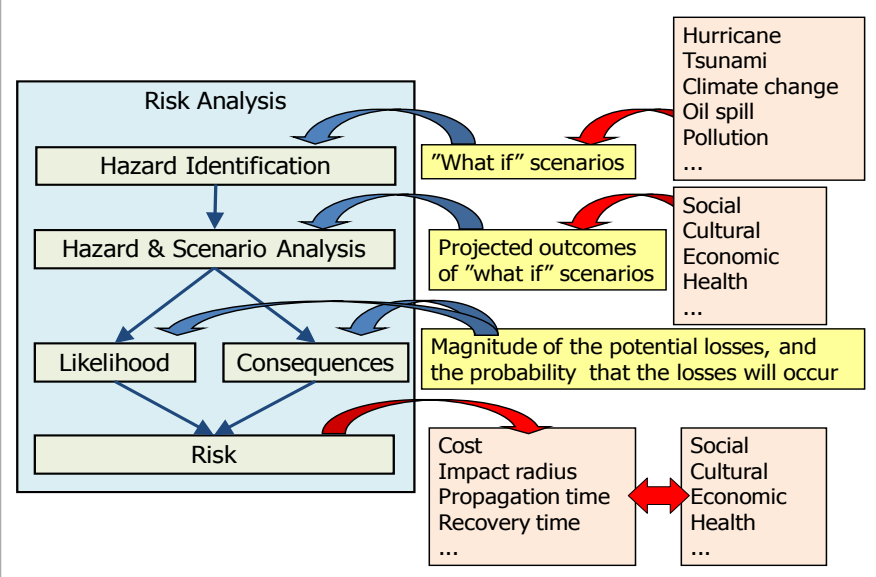

Figure 1: General framework for risk assessment for evaluating hydrologic vulnerability.

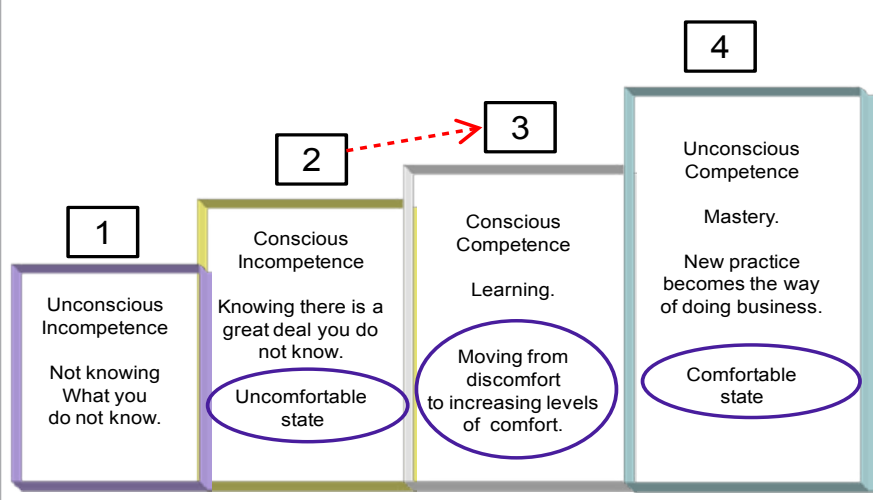

Figure 2: Progression of awareness for addressing the needs.

*Corresponding author: Berrin Tansel, Florida International University, Miami, Florida, USA, Tel: 305348 2928; E-mail: tanselb@fiu.edu

Received December 09, 2013; Accepted December 09, 2013; Published December 17, 2013

Citation: Tansel B (2013) Hydrologic Vulnerability and Preventing Domino Effect Consequences. Hydrol Current Res 4: e113. doi:10.4172/2157-7587.1000e113

Copyright: (c) 2013 Tansel B. This is an open-access article distributed under the terms of the Creative Commons Attribution License, which permits unrestricted use, distribution, and reproduction in any medium, provided the original author and source are credited. 
Citation: Tansel B (2013) Hydrologic Vulnerability and Preventing Domino Effect Consequences. Hydrol Current Res 4: e113. doi:10.4172/2157$7587.1000 \mathrm{e} 113$

Page 2 of 2

conditions; level of hydrologic vulnerability; and the propagation of potential impacts are not clearly understood due to the dynamic nature of vulnerability.

The important questions remain regarding implementation of effective management strategies and policies that address hydrologic vulnerability. These include:

- Protection, restoration, and managing water resources;

- Products and services that can enable local communities to plan and respond variability and change;

- Improving products and services to advance the capabilities for understanding, observation, forecasting and warning for hydrologic events; and

- Support for the existing infrastructure with information, products and services for safe, efficient, and environmentally sound products and management tools.

Water bodies are vulnerable systems where primary impacts can trigger a multitude of secondary impacts creating multidimensional shocks. From a vulnerability management perspective, there is a major gap in knowledge for developing effective land development policies, emergency response strategies, and funding mechanisms to address the increasing state of hydrologic vulnerability. 